\title{
Molecular mutation profile of pfcrt in Plasmodium falciparum isolates imported from Africa in Henan province
}

\author{
Rui-min Zhou, Hong-wei Zhang, Cheng-yun Yang, Ying Liu, Yu-ling Zhao, Su-hua Li, Dan Qian and Bian-li Xu*
}

\begin{abstract}
Background: Anti-malarial drug resistance is a primary public health problem. Haplotypes of pfcrt gene have been implicated to be molecular markers of chloroquine (CQ) resistance. This study aims to explore the prevalence of polymorphisms in pfcrt in Plasmodium falciparum-infected patients imported from Africa in Henan province.

Methods: Blood samples were collected from 502 patients who were infected with P. falciparum returning from Africa in Henan province during 2012-2015. The single nucleotide polymorphisms in pfcrt (codons 72-76) were assessed by nested PCR with DNA sequencing and restriction digestion, the haplotype prevalences were also determined.

Results: Four haplotypes coding 72-76 of pfcrt were found including CVMNK (wild type), CVIET (mutation type), CVIEK (mutation type), and CV M/I N/E/D/K KT (mixed type), with $61.95 \%$ (311/502), $33.07 \%$ (166/502), $0.20 \%$ (1/502), and $4.78 \%$ (24/502) prevalence, respectively. Except mixed type, CVIET and CVIEK were the largest proportion of the mutant type in West Africa, accounting for $44.83 \%$ (91/203), followed by East Africa (8/21, $38.10 \%$ ), North Africa $(4 / 11,36.36 \%)$, Central Africa (36/135, $26.67 \%)$, and South Africa (28/132, $21.21 \%)$. There was significant difference among the groups $\left(X^{2}=23.78, P<0.05\right)$. Mixed type was the largest proportion in North Africa $(9.09 \%)$, followed by Central Africa (6.67 \%), East Africa (4.76\%), South Africa (4.55\%), and West Africa (3.45 \%). There was no significant difference among the groups $\left(x^{2}=2.31, P>0.05\right)$. The position 72 and 73 of pfcrt showed predominance for the wild type with rates of $100 \%(502 / 502)$.

Conclusions: This study identified four haplotypes of pfcrt in P. falciparum-infected patients imported from Africa in Henan province. The prevalence of mutations in the pfcrt was dropped comparing with other people's researches. It establishes fundamental data for detection of $P$. falciparum CQR with molecular markers for the imported $P$. falciparum in China, and it also provides complementary information of CQR for the malaria endemic countries and assesses the evolution of anti-malarial drug resistance.
\end{abstract}

Keywords: Plasmodium falciparum, Pfcrt, Chloroquine resistance (CQR), Imported, Africa, Henan province

\section{Background}

Malaria is an infectious disease that has been present in sub-tropical and temperate countries for much of history. It varies widely in epidemiology and clinical manifestation and is responsible for an estimated 214 million clinical episodes and approximately 438,000 deaths per

\footnotetext{
*Correspondence: bianlixu@163.com

Department of Parasite Disease Control and Prevention, Henan Province Center for Disease Control and Prevention, Zhengzhou 450016, People's Republic of China
}

year, of which approximately $90 \%$ occur in Africa [1]. In 2010, the Ministry of Health in China launched an 'action plan for malaria elimination, with the goals of eliminating malaria in the entire country by the end of 2020 [2]. There has been no indigenous malaria case in Henan province since 2012, whereas the imported cases have increased year-by-year, most of which were imported Plasmodium falciparum from Africa [3-6].

The variability in the spectrum of malarial diseases is the result of several factors, including the distribution 
of the two primary species of malaria parasites ( $P$. falciparum and $P$. vivax), their levels of susceptibility to anti-malarial drugs, the distribution and efficiency of mosquito vectors, climate and other environmental conditions and the behaviour and level of acquired immunity of the exposed human populations [7]. Due to the lack of an effective vaccine, malaria is currently re-infectious and thus its case management depends solely on antimalarials $[8,9]$. Efficacious anti-malarial medicines are critical to malaria control, and continuous monitoring of their efficacy is needed to inform treatment policies in malaria-endemic countries, and to ensure early detection of, and response to, drug resistance [10].

Chloroquine (CQ) was used to combat malaria in 1940s after the Second World War. Since then, it has been considered to be the drug of choice for the treatment of nonsevere, uncomplicated malaria and for chemoprophylaxis [11]. Over the years, CQ has proven to be one of the most successful and important drugs ever deployed against malaria, especially in the highly endemic areas of Africa [12]. The tremendous success of CQ and its heavy use for almost 12 years [13] led to the development of resistance in P. falciparum during the late 1950s [14-18]. CQ resistance $(\mathrm{CQR})$ was reported for the first time at the Thailand-Cambodia border in 1957 and the VenezuelaColombia border in 1959 and eventually spread to other countries throughout the world [19-21]. Soon after, CQR P. falciparum isolates were found to be widespread in malaria-endemic zones, the mutagenic basis of CQR was made evident by several clinical and epidemiological studies [22, 23]. Amino acid polymorphisms have been found in exon 2 of the $p f c r t$ gene at residues 72, 74, 75 and 76 in P. falciparum isolates, suggesting that they may be involved in the genetic characterization of $C Q R$ and $C Q$ sensitivity (CQS). Accordingly, whereas the $\mathrm{C}_{72} \mathrm{~V}_{73} \mathrm{M}_{74}$ $\mathrm{N}_{75} \mathrm{~K}_{76}$ haplotype is considered to be CQS, parasites with polymorphisms at any of these amino acid positions are considered to be CQR [24, 25]. In this study, the prevalence of polymorphisms in pfcrt gene were determined from imported $P$. falciparum patients in Henan province who came back from Africa.

\section{Methods}

\section{Sample collection and DNA extraction}

Blood samples were collected from patients with $P$. falciparum infection prior to treatment. All of the patients came from Africa in year 2012-2015. The final diagnosis was made by microscopic examination of Giemsa-stained thick blood films and nested PCR. For each sample, approximately $200 \mu \mathrm{l}$ of finger-prick blood was spotted on a piece of Whatman 3 M 903 filter paper and airdried. The dried filters were stored in individual plastic bags at $-20{ }^{\circ} \mathrm{C}$ until DNA extraction. Parasite DNA was extracted from the blood filters using a QIAamp DNA mini kit (Qiagen, Valencia, CA, USA) following the manufacturer's instruction.

\section{Nested PCR amplification and DNA sequencing}

Nested PCR [26-28] was performed to amplify the fragments of pfcrt using a DNA thermal cycler (Mastercycler nexus, Eppendorf Ltd, Germany). The primary PCR was performed in a $20-\mu \mathrm{l}$ reaction volume containing $6.0 \mu \mathrm{l}$ $\mathrm{ddH}_{2} \mathrm{O}, 1.0 \mu \mathrm{l}$ each of OuterP1, and OuterP2 primers $(10 \mu \mathrm{mol} / \mathrm{l}), 10 \mu \mathrm{l} 2 \times$ Go Taq Green Master Mix (Promega, USA) and $2.0 \mu \mathrm{l}$ DNA template. The PCR reaction condition was $94{ }^{\circ} \mathrm{C}$ for $3 \mathrm{~min} ; 35$ cycles of $94{ }^{\circ} \mathrm{C}$ for $30 \mathrm{~s}$, $56{ }^{\circ} \mathrm{C}$ for $30 \mathrm{~s}$, and $60^{\circ} \mathrm{C}$ for $60 \mathrm{~s}$; and a final extension at

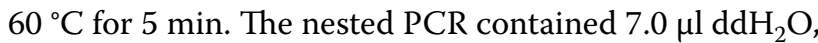
$1.0 \mu \mathrm{l}$ each of InnerP1, and InnerP2 primers $(10 \mu \mathrm{mol} / \mathrm{l})$, $10 \mu \mathrm{l} 2 \times$ Go Taq Green Master Mix, $1.0 \mu \mathrm{l}$ from the first PCR product. The PCR reaction condition was the following: $94{ }^{\circ} \mathrm{C}$ for $3 \mathrm{~min} ; 35$ cycles of $94{ }^{\circ} \mathrm{C}$ for $30 \mathrm{~s}, 48{ }^{\circ} \mathrm{C}$ for $30 \mathrm{~s}$, and $65^{\circ} \mathrm{C}$ for $60 \mathrm{~s}$; and a final extension at $65^{\circ} \mathrm{C}$ for $5 \mathrm{~min}$. The amplified products were purified from an agarose gel and sequenced by Sangon Biotech Co Ltd (Shanghai, China). Primers were also synthesized by Sangon Biotech Co Ltd. Primer sequences are provided in Table 1.

\section{Restriction digest of pfcrt gene amplicons}

Enzymatic digestion of the resulting 145 base pair fragment of the pfcrt amplicons was done using Apo I restriction enzyme (Fermentas Life Sciences) according to the manufacturer's instructions.

\section{Sequencing alignments and data analysis}

Sequence alignments and analysis were carried out using BioEdit software. Amino acid sequences were compared with 3D7 strain, which was obtained from the Chinese Centre for Disease Control and Prevention. The sequences of the amplicons were aligned with 3D7 strain published data from the NCBI database by BLAST analysis. All the data were proceed using Excel to build

\begin{tabular}{|c|c|c|c|}
\hline Gene & Primer & Sequence $\left(5^{\prime}-3^{\prime}\right)$ & Size (bp) \\
\hline \multirow[t]{4}{*}{ pfcrt } & OuterP1 & CCGTTAATAATAAATACACGCAG & 537 \\
\hline & OuterP2 & CGGATGTTACAAAACTATAGTTACC & \\
\hline & InnerP1 & TGTGCTCATGTGTTTAAACTT & 145 \\
\hline & InnerP2 & CAAAACTATAGTTACCAATTTTG & \\
\hline
\end{tabular}


database and the SPSS 17.0 software was used for analysis. The Person's Chi square test was used to determine significance of results. A $P$ value $<0.05$ was considered statistically significant.

\section{Ethical approval}

The study was reviewed and approved by the Project of Medical Science and Technology of Henan province (No. 201304053). Before sampling, the purpose was illustrated to participants and consent was obtained from those who agreed to participate in the survey.

\section{Results}

\section{General characteristics of patients}

Blood samples were collected from 502 patients who were infected with $P$. falciparum returning from 26 countries of Africa to Henan province during 2012-2015. The male:female ratio was 70.71:1 (495/7). The mean age was $38.07 \pm 9.31$ years (range 17-70 years old), of which only 2 patients were older than 60 years and one patient was under 18 years; 502 patients were returned from 26 countries in Africa, the majority $(40.44 \%, 203)$ of whom were from West Africa, followed by Central Africa (26.89\%, $135)$ and South Africa $(26.29 \%, 132)$. The minority were returned from East Africa and North Africa, accounting for $4.18 \%$ (21) and $2.19 \%$ (11), respectively.

\section{PCR-RFLP of the pfcrt gene}

The nested PCR yielded a 145-bp PCR product for each of the 502 samples. These products contained the codons of interest, 72 through 76 , which were analysed both by enzymatic digestion and sequencing. The resulting of Apo I enzymatic digestion yielded two fragments of 31 and $114 \mathrm{bp}$ in the case of the parasite strains containing the wild K76 variant, whereas the mutant T76 variant yielded only one fragment since there was no digestion. Multi-clonal variants yielded three fragments $(145,114$ and 31-bp products). A photo of agarose gel electrophoresis is shown in Fig. 1. Restriction digest of the 502 samples gave the following results: $166(33.07 \%)$ mutant types, $312(62.15 \%)$ wild types and $24(4.78 \%)$ mixed infections, which were also confirmed by sequencing (see Fig. 2).

\section{Pfcrt mutations and haplotypes}

A 145-bp fragment of the $p f c r t$ gene, including residues $72-76$, was successfully sequenced from all the samples. The position 72 and 73 of $p f c r t$ were all the wild type with rates of $100 \%$ (502/502). Four haplotypes coding 72-76 of pfcrt were found, including CVMNK (wild type), CVIET (mutation type), CVIEK (mutation type), and CV $\mathrm{M} / \mathrm{I} \mathrm{N} / \mathrm{E} / \mathrm{D} / \mathrm{K} \mathrm{K} / \mathrm{T}$ (mixed type), with $61.95 \%$ (311/502), $33.07 \%$ (166/502), $0.20 \%(1 / 502)$ and $4.78 \%(24 / 502)$

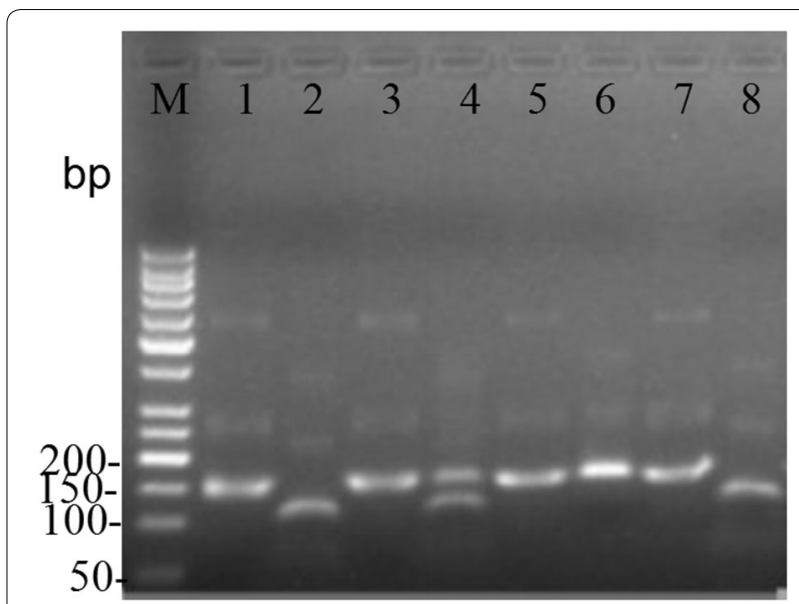

Fig. 1 Identification of the four haplotypes by enzyme digestion. Lanes 1, 3, 5 and 7 were the nested PCR product of the four haplotypes. Lanes 2, 4, 6 and 8 were digested by Apo I. M, molecular marker; lanes 1 and 2, CVMNK; lanes 3 and 4,CVM/I N/E/D/KT/K; lanes 5 and 6 , CVIET; lanes 7 and 8, CVIEK

prevalence, respectively. The detail information and sequencing results of the mutations are shown in Fig. 2 and Table 2, respectively.

\section{Distribution of the CQR-pfcrt haplotypes}

Four haplotypes coding 72-76 of pfcrt were found; only one patient harboured the CVIEK, who was returned from Nigeria in West Africa. The other three haplotypes were found in the every region of Africa; 203 isolates returned from ten countries in West Africa carried four haplotypes: CVMNK, CVIET, CVIEK and CV M/I N/E/D/K K/T, with $51.72 \%$ (105/203), $44.33 \%$ (90/203), $0.49 \%(1 / 203)$ and $3.45 \%(7 / 203)$ prevalence, respectively. 135 isolates returned from six countries in Central Africa carried three haplotypes: CVMNK, CVIET and CV M/I N/E/D/K K/T, with $66.67 \%(90 / 135)$, $26.67 \%(36 / 136)$ and $6.67 \%(9 / 135)$ prevalence, respectively. A total of 132 isolates returned from four countries in South Africa carried three haplotypes: CVMNK, CVIET and CV M/I N/E/D/K K/T, with 74.24\% (98/132), $21.21 \%(28 / 132)$ and $4.55 \%(6 / 132)$ prevalence, respectively. Twenty-one isolates returned from four countries in East Africa carried three haplotypes: CVMNK, CVIET and CV M/I N/E/D/K K/T, with 57.14 \% (12/21), $38.10 \%$ $(8 / 21)$ and $4.76 \%(1 / 21)$ prevalence, respectively. Eleven isolates returned from two countries in North Africa carried three haplotypes: CVMNK, CVIET and CV M/I N/E/D/K K/T, with $54.55 \%(6 / 11), 36.36 \%(4 / 11)$ and $9.09 \%(1 / 11)$ prevalence, respectively. Except mixed type, CVIET and was the largest proportion of the mutant type in West Africa, accounting for $44.33 \%$ (90/203), followed by East Africa (8/21, 38.10 \%), North Africa (4/11, 

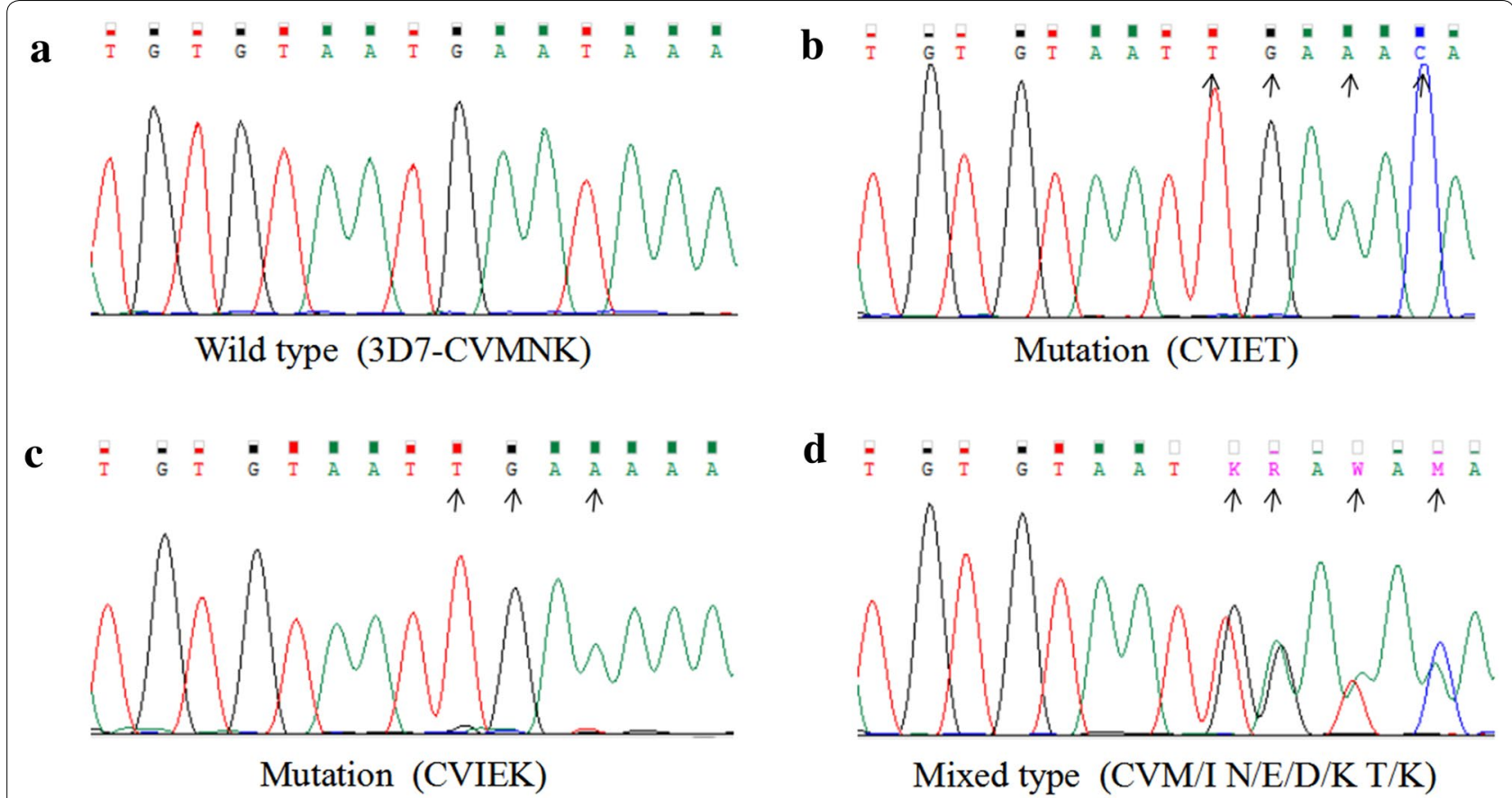

Fig. 2 Sequencing profile of nested PCR product of pfcrt genotypes detected in Plasmodium falciparum isolates imported from Africa in Henan province. a The wild type. The haplotype named CVMNK was got from 3D7. b and c The mutation. The haplotype was named CVIET and CVIEK, respectively. $\mathbf{d}$ The mixed type. The position was showed by degenerate base. The haplotype was named CVM/I N/E/D/KT/K. The mutation position is indicated by the arrow

$36.36 \%)$, Central Africa (36/135, $26.67 \%)$ and South Africa (28/132, $21.21 \%)$. There was significant difference among the groups $\left(\mathrm{X}^{2}=23.78, P<0.05\right)$. There was the largest proportion of the mixed type in North Africa (9.09\%), followed by Central Africa (6.67\%), East Africa (4.76\%), South Africa (4.55\%) and West Africa (3.45\%). There was no significant difference among the groups $\left(x^{2}=2.31, P>0.05\right)($ see Table 2$)$.

\section{Discussion}

Information on the distribution and patterns of antimalarial drug resistance is essential for implementation of effective malaria control programmes and disease surveillance in all malaria-endemic areas of the world. Early detection of occurrence and spreading of antimalarial drug resistance would be greatly enhanced by the application of valid anti-malarial resistance molecular markers. CQ has been used widely in African regions for several decades and formed a strong selection pressure on parasite populations. The World Health Organization advocated a complete ban on artemisinin monotherapy for uncomplicated malaria in 2006 [29]. The national drug policy of China was updated in 2009, and first-line drugs currently used to treat falciparum malaria are ACT, which includes dihydroartemisininpiperaquine (DHA-PIP), artesunate+amodiaquine, artemisinin-naphthoquine phosphate and artemisininpiperaquine [30]. Among the candidate genes investigated to date, $p f c r t$ mutation is widely acceptable as a reliable marker of CQR in P. falciparum in epidemiological studies [23, 31]. So it is important to understand the molecular mutation profiles of P. falciparum parasite for anti-malarial drug resistance and use this foundational information for detection of molecular pattern.

For CQR P. falciparum, two principal haplotypes, with the amino acid sequences $C_{72} V_{73} I_{74} E_{75} T_{76}$ and $S_{72}$ $V_{73} M_{74} N_{75} T_{76}[24,25]$ are widely distributed. Due to the widespread yet structured present-day distribution across $P$. falciparum-endemic zones across the globe, these two haplotypes are hypothetically considered to be CQR mother haplotypes and the other minor haplotypes are believed to have been derived from them [24, 25]. It has been established that CVIET and SVMNT are widely prevalent; whether all of the other minor haplotypes were derived from these two or evolved independently is still an open question.

Mutations in $p f c r t$ are connected to resistance of antimalarial medication, including $\mathrm{CQ}$, amodiaquine $(\mathrm{AQ})$ and lumefantrine (LU), and the haplotypes of pfcrt CVIET and SVMNT have been implicated [32]. The pfcrt CQR haplotypic view in Africa is completely biased towards the CVIET haplotype, owing to the wide usage 
Table 2 Distribution of the CQR-pfcrt haplotypes from Africa-imported cases

\begin{tabular}{|c|c|c|c|c|c|}
\hline Region & Country & Total & CVMNK & CVIET & CV M/I N/E/D/K K/T \\
\hline \multirow[t]{3}{*}{ North Africa } & & 11 & $6(54.55 \%)$ & $4(36.36 \%)$ & $1(9.09 \%)$ \\
\hline & Sudan & 9 & $6(66.67 \%)$ & $3(33.33 \%)$ & $0(0.00 \%)$ \\
\hline & Libya & 2 & $0(0.00 \%)$ & $1(50.00 \%)$ & $1(50.00 \%)$ \\
\hline \multirow[t]{5}{*}{ East Africa } & & 21 & $12(57.14 \%)$ & $8(38.10 \%)$ & $1(4.76 \%)$ \\
\hline & Ethiopia & 2 & $0(0.00 \%)$ & $2(100 \%)$ & $0(0.00 \%)$ \\
\hline & Kenya & 3 & $3(100 \%)$ & $0(0.00 \%)$ & $0(0.00 \%)$ \\
\hline & Tanzania & 10 & $6(60.00 \%)$ & $3(30.00 \%)$ & $1(10.00 \%)$ \\
\hline & Uganda & 6 & $3(50.00 \%)$ & $3(50.00 \%)$ & $0(0.00 \%)$ \\
\hline \multirow[t]{5}{*}{ South Africa } & & 132 & $98(74.24 \%)$ & $28(21.21 \%)$ & $6(4.55 \%)$ \\
\hline & Angola & 101 & $69(68.32 \%)$ & $26(25.74 \%)$ & $6(5.94 \%)$ \\
\hline & Zimbabwe & 1 & $1(100 \%)$ & $0(0.00 \%)$ & $0(0.00 \%)$ \\
\hline & Mozambique & 10 & 9 (90.00\%) & $1(10.00 \%)$ & $0(0.00 \%)$ \\
\hline & Zambia & 20 & 19 (95.00 \%) & $1(5.00 \%)$ & $0(0.00 \%)$ \\
\hline \multirow[t]{11}{*}{ West Africa } & & $203\left(202+1^{a}\right)$ & 105 (51.72\%) & 90 (44.33 \%) & $7(3.45 \%)$ \\
\hline & Benin & 5 & $1(20.00 \%)$ & $4(80.00 \%)$ & $0(0.00 \%)$ \\
\hline & Togo & 5 & $4(80.00 \%)$ & $1(20.00 \%)$ & $0(0.00 \%)$ \\
\hline & The Republic of Guinea & 33 & $21(63.64 \%)$ & $11(33.33 \%)$ & $1(3.03 \%)$ \\
\hline & Ghana & 23 & 19 (82.61 \%) & $3(13.04 \%)$ & $1(4.35 \%)$ \\
\hline & Ivory Coas & 10 & $7(70.00 \%)$ & $3(30.00 \%)$ & $0(0.00 \%)$ \\
\hline & Liberia & 23 & $1(4.35 \%)$ & 22 (95.65 \%) & $0(0.00 \%)$ \\
\hline & Mali & 4 & $2(50.00 \%)$ & $1(25.00 \%)$ & $1(25.00 \%)$ \\
\hline & Nigeria & $74\left(73+1^{\mathrm{a}}\right)$ & $40(54.05 \%)$ & $31(41.89 \%)$ & $2(2.7 \%)$ \\
\hline & Sierra Leone & 25 & $9(36.00 \%)$ & $14(56.00 \%)$ & $2(8.00 \%)$ \\
\hline & Burkina Faso & 1 & $1(100 \%)$ & $0(0.00 \%)$ & $0(0.00 \%)$ \\
\hline \multirow{7}{*}{ Central Africa } & & 135 & $90(66.67 \%)$ & $36(26.67 \%)$ & $9(6.67 \%)$ \\
\hline & Equatorial Guinea & 75 & $58(77.33 \%)$ & $11(14.67 \%)$ & $6(8.00 \%)$ \\
\hline & Congo & 23 & $11(47.83 \%)$ & $12(52.17 \%)$ & $0(0.00 \%)$ \\
\hline & Gabon & 6 & $1(16.67 \%)$ & $5(83.33 \%)$ & $0(0.00 \%)$ \\
\hline & Cameroon & 23 & $14(60.87 \%)$ & $6(26.09 \%)$ & $3(13.04 \%)$ \\
\hline & Chad & 7 & $5(71.43 \%)$ & $2(28.57 \%)$ & $0(0.00 \%)$ \\
\hline & Central Africa Republic & 1 & $1(100 \%)$ & $0(0.00 \%)$ & $0(0.00 \%)$ \\
\hline
\end{tabular}

a There was only one P. falciparum isolate from Nigeria with CVIEK haplotype

of CQ and AQ drugs in many African countries [33]. This study indicated $33.07 \%$ isolates harboured the $p f c r t$ mutant CVIET, while $4.98 \%$ isolates had the CVIETderived haplotypes, CV M/I N/E/D/K K/T (4.78 \%) and CVIEK (0.20\%). The two main methods, namely Apo I enzymatic digestion and the sequencing, employed here to analyse the pfcrt gene status of the parasite strains from the study participants served to confirm or complement findings from each of the methods. There was no SVMNT haplotype found in isolates returned from Africa in this study. The pfcrt SVMNT is more commonly found in South America and some Asian countries [34], but rarely reported from the African continent. The result in this study that no SVMNT haplotype found in isolates returned from Africa confirm the above conclusion. Except mixed type, there was the largest proportion of the mutant type in West Africa, accounting for $44.83 \%$ (CVIET and CVIEK, 91/203); this difference might come from the amount of AQ used in different regions. In this study, $4.78 \%$ mixed type (wild type and mutant type) of pfcrt was detected in falciparum malaria isolates returned from ten countries (Angola, Equatorial Guinea, Cameroon, Nigeria, Sierra Leone, The Republic of Guinea, Ghana, Mali, Libya, Tanzania). It was reported that $6.62 \%$ mixed type of pfcrt was found in malaria isolates from Bioko Island, Equatorial Guinea [35], which was not reported in neighbouring countries [36-39]. This study enriched the distribution of the mixed type of pfcrt. The CVIEK haplotype was reported to be detected in Central Africa Republic, Gabon, Sudan, Thailand, and Eastern India [40-46]. In this study, among 502 isolates, only one patient harboured the CVIEK haplotype, who 
returned from Nigeria. It was the first report that CVIEK haplotype found in West Africa.

Five-hundred and two patients were returned from 26 countries in Africa; half of them (250/502, $49.80 \%)$ were from three countries: Angola (101), Equatorial Guinea (75) and Nigeria (74). The remainder returned from the other 23 countries, but there were 16 countries from which fewer than or equal to ten patients returned, so it was hard to fully explain the situation of the $p f c r t$ in each country.

In regions with high malaria endemic, the withdrawal of CQ as first-line treatment of P. falciparum infections has typically led to the restoration of $C Q$ susceptibility through the reexpansion of the wild type allele of pfcrt at the expense of less fit mutant alleles carrying the CQR marker. In French Guiana, despite the fixation of the $\mathrm{K} 76 \mathrm{~T}$ allele, the prevalence of CQR isolates progressively dropped from $>90 \%$ to $<30 \%$ during 17 years after CQ withdrawal in 1995 [47]. In this study, the prevalence of CVIET haplotype among 502 isolates was $33.07 \%$, which was consistent with the above results. Gharbi et al. reconfirmed this conclusion, they carried out a longitudinal study assessing the return of chloroquine susceptibility of $P$. falciparum in isolates from travellers returning from West and Central Africa, during 2000-2011, the prevalence of the fcrt76T mutant genotype significantly decreased [48, 49].

Travelers who return from endemic countries infected with malaria often present with low immunity against the parasites and there is no risk of re-infection, so they are a particularly valuable source of information. Many settings in endemic countries lack the financial resources necessary to maintain a sustainable, accurate and reliable anti-malarial resistance surveillance system, resulting in gaps in the spatial and temporal available information. This study can provide complementary information of $\mathrm{CQR}$ for the malaria endemic countries.

\section{Conclusions}

This study reports the prevalence of polymorphisms in pfcrt gene in blood sample obtained from $P$. falciparum-infected patients imported from Africa in Henan province, and it illustrates the situation of $C Q R$ for the patients of $P$. falciparum imported from Africa, which is essential for implementation of effective malaria elimination programmes and drug resistance surveillance in Henan province. Continuous molecular surveillance with $p f c r t$ gene of imported $P$. falciparum as an anti-malarial drug resistance marker is exceedingly recommended in China. It will be useful for the malaria endemic countries to assess the evolution of anti-malarial drug resistance and provide complementary information of CQR.
Authors' contributions

RMZ was responsible for the molecular genetic analysis and data interpretation and drafted the manuscript. HWZ and BLX conceived the study and revised the manuscript. CYY and $Y L$ participated in sample collection and sample detection. HWZ and YLZ provided the administrative coordination. SUL and DQ participated in the data collection and analysed the data. All authors read and approved the final manuscript.

\section{Acknowledgements}

The study was supported by the Project of Medical Science and Technology of Henan Province, China (No. 201304053). The funders had no role in study design, data collection and analysis, decision to publish, or preparation of the manuscript.

\section{Competing interests}

The authors declare that they have no competing interests.

Received: 17 February 2016 Accepted: 21 April 2016

Published online: 10 May 2016

References

1. WHO. World malaria report. Geneva: World Health Organization; 2015. pp. 280.

2. China action plan for malaria elimination. http://www.moh.gov.cn/ publicfiles/business/htmlfiles/mohjbyfkzj/s3593/201005/47529.htm.

3. Yang CY, Lu DL, Zhou RM, Qian D, Liu Y, Zhang HW. Current status and epidemiological characteristics of imported malaria in Henan province (in Chinese). China Trop Med. 2014;14:565-7.

4. Liu Y, Zhou RM, Qian D, Yang CY, Zhang HW. Analysis of malaria epidemiological characteristics in Henan province from 2005 to 2013 (in Chinese). Zhonggou Ji Sheng Chong Xue Yu Ji Sheng Chong Bing Za Zhi. 2014;32:419-22.

5. Yang CY, Lu DL, Zhou RM, Liu Y, Zhang HW, Zhao YL. Malaria situation in Henan province in 2013 (in Chinese). Zhonggou Ji Sheng Chong Xue Yu Ji Sheng Chong Bing Za Zhi. 2014;32:370-2.

6. Zhang L, Feng J, Xia ZG. Malaria situation in the People's Republic of China in 2013 (in Chinese). Zhonggou Ji Sheng Chong Xue Yu Ji Sheng Chong Bing Za Zhi. 2014;32:407-13.

7. Bloland PB. Drug resistance in malaria, WHO/CDS/CRS/DRS. Geneva; 2001, p. 32.

8. WHO. Chemotherapy of malaria and resistance to antimalarials: report of a WHO scientific group. Geneva: World Health Organization; 1973. WHO Tech Rep Ser. 529. pp. 1-121.

9. WHO. Advances in malaria chemotherapy. Geneva: World Health Organization; 1984. WHO Tech Rep Ser 711. pp. 1-218.

10. Malaria disease burden in SEA region. http://www.searo.who.int/EN/Section10/Section21/Section340_4018.htm.

11. Telgt DS, van der Ven AJ, Schimmer B, Droogleever-Fortuyn HA, Sauerwein RW. Serious psychiatric symptoms after chloroquine treatment following experimental malaria infection. Ann Pharmacother. 2005;39:551-4.

12. Wellems TE, Plowe CV. Chloroquine resistant malaria. J Infect Dis. 2001;184:770-6.

13. Wongsrichanalai C, Pickard AL, Wernsdorfer WH. Epidemiology of drug resistant malaria. Lancet Infect Dis. 2002;2:209-18.

14. Maberti S. Development of resistance to pyrimethamine. Presentation of 15 cases studied in Trujillo, Venezuela. Arch Venez Med Trop Parasitol Med. 1960;3:239-59.

15. Moore DV, Lanier JE. Observations on the two Plasmodium falciparum infections with an abnormal response to chloroquine. Am J Trop Med Hyg. 1961;10:5-9.

16. Young MD, Moore DV. Chloroquine resistance in Plasmodium falciparum. Am J Trop Med Hyg. 1961;10:317-20.

17. Reyes S. Malarial infections with Plasmodium falciparum resistant to chloroquine treatment. The situation in Brazil (1960-1981). Rev Bras Malariol Doencas Trop. 1981;33:109-30.

18. Peters W. Chemotherapy and drug resistance in malaria. 2nd ed. London: Academic Press; 1987. p. 542. 
19. Wernsdorfer WH, Payne D. The dynamics of drug resistance in Plasmodium falciparum. Pharmacol Ther. 1991;50:95-121.

20. Mehlotra RK, Fujioka H, Roepe PD. Evolution of a unique Plasmodium falciparum chloroquine-resistance phenotype in association with pfcrt polymorphism in Papua New Guinea and South America. Proc Natl Acad Sci USA. 2001;98:12689-94.

21. Ridley RG. Medical need, scientific opportunity and the drive for antimalarial drugs. Nature. 2002;415:686-93.

22. Wellems T, Walker-Jonah A, Panton $\sqcup$. Genetic mapping of the chloroquine resistance locus on Plasmodium falciparum chromosome 7. Proc Natl Acad Sci USA. 1991;88:3382-6.

23. Fidock DA, Nomura T, Talley AK, Cooper RA, Dzekunov SM, Ferdig MT, et al. Mutations in the P. falciparum digestive vacuole transmembrane protein PfCRT and evidence for their role in chloroquine resistance. Mol Cell. 2000;6:861-71.

24. Awasthi G, Prasad GB, Das A. Population genetic analyses of pfcrt haplotypes reveal the evolutionary history of chloroquineresistant malaria in India. Int J Parasitol. 2011;41:705-9.

25. Awasthi G, Satya GBK, Das A. pfcrt haplotypes and the evolutionary history of chloroquine-resistant Plasmodium falciparum. Mem Inst Oswaldo Cruz. 2012;107:129-34.

26. Djimde A, Doumbo OK, Cortese JF, Kayentao K, Doumbo S, Diourte Y, et al. A molecular marker for chloroquine-resistant falciparum malaria. N Engl J Med. 2001;344:257-63.

27. Kublin JG, Dzinjalamala FK, Kamwendo DD, Malkin EM, Cortese JF, Martino LM, et al. Molecular markers for failure of sulfadoxine-pyrimethamine and chlorproguanil-dapsone treatment of Plasmodium falciparum malaria. J Infect Dis. 2002;185:380-8.

28. WHO. Methods and techniques for clinical trials on antimalarial drug efficacy: genotyping to identify parasite populations. Geneva: World Health Organization; 2008. http://www.who.int/malaria/resistance.

29. WHO. Guidelines for the treatment of malaria. Geneva: World Health Organization; 2010

30. Antimalarial drug policy in China. http://www.moh.gov.cn/publicfiles/ business/htmlfiles/mohjbyfkzj/s3594/200907/41610.htm.

31. Lakshmanan V, Bray PG, Verdier-Pinard D, Johnson DJ, Horrocks P, Muhle RA, et al. A critical role for pfcrt K76T in Plasmodium falciparum verapamilreversible chloroquine resistance. EMBO J. 2005;24:2294-305.

32. Mwai L, Kiara SM, Abdirahman A, Pole L, Rippert A, Diriye A, et al. In vitro activities of piperaquine, lumefantrine, and dihydroartemisinin in Kenyan Plasmodium falciparum isolates and polymorphisms in pfcrt and pfmdr1. Antimicrob Agents Chemother. 2009;53:5069-73.

33. Djimde AA, Barger B, Kone A, Beavogui AH, Tekete M, Fofana B, et al. A molecular map of chloroquine resistance in Mali. FEMS Immunol Med Microbiol. 2010;58:113-8.

34. Sa JM, Twu O. Protecting the malaria drug arsenal: halting the rise and spread of amodiaquine resistance by monitoring the pfcrt SVMNT type. Malar J. 2010;9:374.

35. Li J, Chen J, Xie D, Eyi UM, Matesa RA, Obono MM, et al. Molecular mutation profile of pfcrt and pfmdr1 in Plasmodium falciparum isolates from Bioko Island, EquatorialGuinea. Infect Genet Evol. 2015;36:552-6.

36. Gbotosho GO, Folarin OA, Bustamante C, da Silva LH, Mesquita E, Sowunmi A, et al. Different patterns of pfcrt and pfmdr1 polymorphisms in P. falciparum isolates from Nigeria and Brazil: the potential role of antimalarial drug selection pressure. Am J Trop Med Hyg. 2012;86:211-3.
37. Ali IM, Netongo PM, Atogho-Tiedeu B, Ngongang EO, Ajua A, Achidi EA, et al. Amodiaquine-artesunate versus artemether-lumefantrine against uncomplicated malaria in children less than 14 years in Ngaoundere, North Cameroon: efficacy, safety, and baseline drug resistant mutations in pfcrt, pfmdr1, and pfdhfr genes. Malar Res Treat. 2013;2013:234683.

38. Mayengue PI, Kalmbach Y, Issifou S, Kremsner PG, Ntoumi F. No variation in the prevalence of point mutations in the pfcrt and pfmdrl genes in isolates from Gabonese patients with uncomplicated or severe Plasmodium falciparum malaria. Parasitol Res. 2007;100:487-93.

39. Mawili-Mboumba DP, Ndong Ngomo JM, Maboko F, Guiyedi V, Mourou Mbina JR, Kombila M, et al. pfcrt 76T and pfmdr1 86Y allele frequency in Plasmodium falciparum isolates and use of self-medication in a rural area of Gabon. Trans R Soc Trop Med Hyg. 2014;108:729-34.

40. Menard D, Djalle D, Yapou F, Manirakiza A, Talarmin A. Frequency distribution of antimalarial drug-resistant alleles among isolates of Plasmodium falciparum in Bangui, Central African Republic. Am J Trop Med Hyg. 2006;74:205-10.

41. Rafika Z, Jean BL, Faustin L, Ulrick B, Edgard BN, Fousseyni STN. In vitro antimalarial susceptibility and molecular markers of drug resistance in Franceville. Gabon. BMC Infect Dis. 2012;12:307.

42. Summers RL, Nash MN, Martin RE. Know your enemy: understanding the role of pfcrt in drug resistance could lead to new antimalarial tactics. Cell Mol Life Sci. 2012;69:1967-95.

43. Awasthi G, Das A. Genetics of chloroquine-resistant malaria: a haplotypic view. Mem Inst Oswaldo Cruz. 2013;108:947-61.

44. Chavachol S, Peerapan T, Naruemon S, Rommanee K, Nantana S, Saovanee $\mathrm{L}$, et al. Role of Plasmodium falciparum chloroquine resistance transporter and multidrug resistance 1 genes on in vitro chloroquine resistance in isolates of Plasmodium falciparum from Thailand. Am JTrop Med Hyg. 2011;85:606-11.

45. Sabyasachi D, Santanu KM, Satyajit T, Sourav C, Sandeep KD, Debasis M, et al. Double mutation in the pfmdrl gene is associated with emergence of chloroquine-resistant Plasmodium falciparum malaria in Eastern India. Antimicrob Agents Chemother. 2014;58:5909-15.

46. Nobuyuki T, Kazuyuki T, Takahiro T, Mawuli D, Lek D, Boualam K, et al. Large-scale survey for novel genotypes of Plasmodium falciparum chloroquine-resistance gene pfcrt. Malar J. 2012;11:92.

47. Pelleau S, Moss EL, Dhingra SK, Volney B, Jasteras J, Gabryszewski SJ, et al. Adaptive evolution of malaria parasites in French Guiana: reversal of chloroquine resistance by acquisition of a mutationin pfcrt. Proc Natl Acad Sci USA. 2015;112:11672-7.

48. Gharbi M, Flegg JA, Hubert V, Kendjo E, Metcalf JE, Bertaux L, et al. Longitudinal study assessing the return of chloroquine susceptibility of Plasmodium falciparum in isolates from travellers returning from West and Central Africa, 2000-2011. Malar J. 2013;12:35.

49. Gharbi M, Flegg JA, Pradines B, Berenger A, Ndiaye M, Abdoulaye AD, et al. Surveillance of travellers: an additional tool for tracking antimalarial drug resistance in endemic countries. PLoS ONE. 2013;8:e77775.

\section{Submit your next manuscript to BioMed Central and we will help you at every step:}

- We accept pre-submission inquiries

- Our selector tool helps you to find the most relevant journal

- We provide round the clock customer support

- Convenient online submission

- Thorough peer review

- Inclusion in PubMed and all major indexing services

- Maximum visibility for your research

Submit your manuscript at www.biomedcentral.com/submit
BioMed Central 